\title{
Impact of Female Literacy and Maternal Nutrition on Birth Weight of Infant in Rural Areas of Uttar Pradesh
}

\author{
Garima Jain ${ }^{1 *}$,Mohd Zuber ${ }^{2}$, Vikram Bisen ${ }^{3}$ \\ ${ }^{1}$ Department of Management, BIMS, Lucknow, UP, India \\ ${ }^{2}$ Department of Public Health, College of Health Sciences, Saudi Electronic University, Kingdom of Saudi Arabia \\ ${ }^{3}$ Department of Management, VIMT, Lucknow, UP, India
}

"Corresponding author: Garima Jain, Department of Management, BIMS, Lucknow, UP, India.Tel: +919451176404;Email: gjain18@yahoo.co.in

Citation: Jain G, Zuber M, Bisen V(2017) Impact of Female Literacy and Maternal Nutrition on Birth Weight of Infant in Rural Areas of Uttar Pradesh, India. J Community Med Public Health: CMPH-107. DOI: 10.29011/CMPH-107/100007

Received Date: 20 July, 2017; Accepted Date: 05 August, 2017; Published Date: 14 August, 2017

\begin{abstract}
Objective: To evaluate the impact of Female Literacy (FL), an integrated objective of Integrated Child Development Services Scheme (ICDS) and maternal nutrition on birth weight of infants.

Methodology: 43 ICDS and 30 non-ICDS villages of Block Mohanlalganj in Lucknow, Uttar Pradesh was included in the study. 5289 pregnancies were registered during the study in these villages. Two main groups were made on basis of female literacy (FL) designated as FL and non-FL group. The FL group was further divided into two groups on basis of nutrition supplementation. Live births with weight recorded within $48 \mathrm{hr}$ of delivery formed the study subjects.

Results: The FL with nutrition supplemented group mother's gained 100g more in pregnancy and birth weight was higher by $58 \mathrm{~g}$ $(\mathrm{p}<0.05)$ as compared to un-supplemented FL group mothers. Birth weight in un-supplemented FL group was $25 \mathrm{~g}$ higher as compared to non-FL group. FL supplemented group women had a significantly smaller proportion of low birth weight babies (14.4\%) compared to FL un-supplemented group (20.4\%) and non-FL group women $(26.3 \%)$. The corresponding prevalence of pre-term births was 2.0, 2.4 and 4.3\%, respectively $(\mathrm{p}<0.001)$. Multiple regression analysis showed that increased weight gain in pregnancy, length of gestation, caloric intake and term hemoglobin were significantly associated with birth weight.
\end{abstract}

Conclusion: Female literacy and maternal nutrition had direct impact on birth weight of infants.

Keywords: Birth Weight of Infants; Integrated Child Development Services Scheme; Female Literacy; Maternal Nutrition

\section{Introduction}

Literacy is key for socio-economic progress of the society [1], and according to literatures, the Indian literacy rate grew to 74.04 in 2011 from 12\% at the end of 1947 [Census of India 2011]. Although this was a greater than fivefold improvement, the level is well below the world average literacy rate of $84 \%$, and India currently has the largest illiterate population as compared to any nation in the world. Studies show that Literacy is directly related to the status of a woman, her age at marriage, her decision power and to mention especially capability to access health care services.

Literacy not only increases women's self-confidence but also makes them more exposed to information and thereby altering the way others respond to them. Female literacy improves their healthseeking behavior, makes them aware of nutritional requirements thereby improving the health and chances of survival of both - the mother and the infant [2].There is much to praise in India's efforts to tackle high female illiteracy. National female literacy has risen steadily from 7.9 percent in 1951 to 65.46 percent in 2011.

The Government of India in 1975 launched the Integrated Child Development Services (ICDS) in a planned manner to cover all the areas. Female Literacy (FL) was an integrated objective of this scheme with equitable importance on maternal nutrition their impact as a whole on birth weight of infants [1]. Uttar Pradesh remains one of the least developed states in the country on account of its large population, low productivity levels and per 


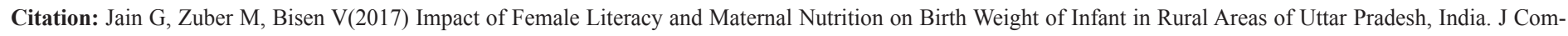
munity Med Public Health: CMPH-107.

capita income. The literacy rate in UP, stands at $67.68 \%$ in 2011 against the national rate of $74.04 \%$ and female literacy rates in UP are as low as $57.18 \%$ compared to the all India rates of $65.46 \%$. Furthermore, UP's performance for utilization of complete antenatal care is only 5\% compared to India's $15 \%$. It is clear therefore, that UP being the largest state in terms of its population size, it's 166.4 million, comprising $17 \%$ of India's population; it's demographic backwardness needs to be the focus of attention and concerted efforts need to be made towards enhancement of female literacy thereby successfully bring about the desired effect on their nutritional intake and subsequently their own and infants health [3].

The ICDS scheme was also planned to cover urban slums. This is the largest direct literacy, nutrition and health input program in the world for children and pregnant and lactating women [1].The main object of this program is to enhance literacy of women, thus improving nutritional and health status of infant and mother and reduce mortality, morbidity and malnutrition rate of mother and child. Thus, the present study was aimed to evaluate the impact of female literacy (an integrated objective of ICDS program) and maternal nutrition on birth weight of infants along with the impact of nutrition supplement on weight gain in pregnancy.

\section{Methodology}

\section{Profile of Selected Study Areas of a District of Uttar Pradesh}

The present study was undertaken in Block name Mohanlalganj in District Lucknow of Uttar Pradesh. 43 villages with ICDS program (population 33770) and the adjoining non-ICDS 30 villages (population 32307) [Census of India 2011] were taken. For evaluating the impact of Female literacy, women of ICDS villages and non-ICDS villages were compared. While to evaluate the impact nutrition supplementation among literate female, the supplemented women of ICDS villages of block Mohanlalganj were compared against those who did not receive the supplementation during pregnancy, as other ICDS inputs were similar in both the groups. The study however had some weaknesses:(a) quality, composition and required amount for supplement could not be controlled,(b)the criteria for selection of women was based on socio-economic status and caste (4-5\% more from the scheduled caste group and lower socio-economic families in nutrition supplementation group), and (c) sharing of supplemented food in these families could not be checked personally except by verbal enquiry.Besides the nutrition supplement to pregnant women, pre-school children received nonformal education and nutrition supplementation in the ICDS block. The women in addition received education on health and diet and were provided antenatal check-up which formed our FL group. The data for the study were collected from 2011 to 2016.

Group Allocation: The distribution of studied villages was done on basis of female literacy and nutrition supplementation provided under ICDS scheme of Govt. of India.

- Group A: These included participants from villages where, Females literacy and maternal nutritional supplementation was done under ICDS scheme.

- Group B: These included participants from villages where only Female literacy was done under ICDS scheme and no maternal nutritional supplementation was done.

- Group C: These included participants from villages neither Females literacy nor maternal nutritional supplementation was done as ICDS scheme was not implemented.

\section{Inclusion Criteria for Villages and Women participants:}

- Villages withmaximum number of married / pregnant women. Marriedwomen in average same age group between 20-35 yrs. accessibility to nearby Anganwadi centre.

- Women participantsfrom low socio-economic families and same cast.With on average same pre-pregnancy health parameters and same number of living childrenhaving live infant birthon average having similar health parameters like weight and height.

\section{Data Collection}

Data collection for study included a Schedule along with Medical records of studied women available with Anganwadi workers. A sample of theSchedule used for collecting data is as follows:

\section{Anthropometeric measurements}

Maternal height, weight and mid-arm circumference were measured as per standard techniques using Chattilon weighing scale (USA), anthropometric rod and fiber glass tape, respectively. Birth weight was recorded on a modified Tansy scale[1,4,5]. Abdominal girth was measured by fiber glass tape at the level of umbilicus by crossover technique. Pre-pregnancy weight, mid-arm circumference and height measurements were available for these study women.

\section{Hemoglobin estimation and dietary assessment}

Hemoglobin was estimated by cyanmethemoglobin method. Dietary survey was done by $24 \mathrm{hr}$ recall method using standard utensils. These estimations were undertaken in all pregnant women. During pregnancy women were examined at $16 \pm 2,28 \pm 2$ and $36 \pm 2$ weeks of gestation and also within $48 \mathrm{hr}$ of delivery for estimation of gestational age at the time of birth and birth weight.

\section{Statistical Methods}

Means, standard deviation, ANOVA and multiple regression analysis were performed on SPSS 19 (Statistical Package for Social Sciences) Analysis Software. 
Citation: Jain G, Zuber M, Bisen V(2017) Impact of Female Literacy and Maternal Nutrition on Birth Weight of Infant in Rural Areas of Uttar Pradesh, India. J Community Med Public Health: CMPH-107.

\section{Results}

\section{Socio-demographic and Biological Characteristics (Table 1)}

\begin{tabular}{|c|c|c|c|c|c|c|}
\hline \multicolumn{5}{|c|}{ Table I - Socio-demographic and Biological pre-pregnancy Characteristics of Women in FL and } & \multicolumn{2}{|c|}{ Non-FL Areas (Mean \pm SD) } \\
\hline \multirow{2}{*}{\multicolumn{2}{|c|}{ Characteristics }} & \multicolumn{2}{|c|}{ FL Group } & \multirow{2}{*}{$\begin{array}{c}\text { Non-FL } \quad(n=1748) \\
\text { (C) }\end{array}$} & \multirow[b]{2}{*}{ p value Tukey'stest } & \multirow{2}{*}{$\begin{array}{l}\text { Significance } \\
\text { between }\end{array}$} \\
\hline & & $\begin{array}{c}\text { Supplemented (n }= \\
1282)(A)\end{array}$ & $\begin{array}{l}\text { Unsupplemented (n } \\
=1826)(B)\end{array}$ & & & \\
\hline \multicolumn{2}{|c|}{ 1. Age (years) } & $26.1 \pm 5.6$ & $26.1 \pm 6.0$ & $24.9 \pm 5.8$ & $<0.0001$ & C vs A \& B \\
\hline \multirow{2}{*}{ 2. Education (years) } & Females & $3.7 \pm 2.3$ & $2.5 \pm 3.0$ & $1.8 \pm 3.07$ & $<0.0001$ & $\mathrm{~A}$ vs $\mathrm{B} \& \mathrm{C}$; B vs $\mathrm{C}$ \\
\hline & Males & $5.5 \pm 4.9$ & $5.7 \pm 4.8$ & $5.0 \pm 4.7$ & $<0.0001$ & $\mathrm{C}$ vs $\mathrm{A} \& \mathrm{~B}$ \\
\hline \multicolumn{2}{|c|}{ 3. Living children } & $2 \pm 1$ & $2 \pm 1$ & $2 \pm 1$ & - & - \\
\hline \multirow{3}{*}{ 4.Pre-pregnancy } & Weight $(\mathrm{kg})$ & $42.1 \pm 3.9$ & $42.6 \pm 4.2$ & $41.3 \pm 4.9$ & $<0.0001$ & $\mathrm{C}$ vs $\mathrm{A} \& \mathrm{~B}$ \\
\hline & Height $(\mathrm{cm})$ & $149.6 \pm 4.1$ & $149.4 \pm 4.1$ & $148.9 \pm 5.0$ & $<0.0001$ & C vs A \& B \\
\hline & MAC (cm) & $22.0 \pm 1.6$ & $22.3 \pm 1.7$ & $21.9 \pm 1.8$ & $<0.002$ & B vs $\mathrm{C}$ \\
\hline
\end{tabular}

Table 1: A comparison of age, education and number of living children in the FL and non-FL group is depicted.

\section{Anthropometry During Pregnancy}

The mean weight gain during pregnancy was $7.5 \pm 1.0$, $6.3 \pm 0.9$ and $5.6 \pm 1.1 \mathrm{~kg}$ for the nutrition supplemented and unsupplemented women of FL group and non-FL group, respectively Table 2. Gain in weight of $>6.0 \mathrm{~kg}$ was observed in $72.3 \%, 69.5 \%$ and $32.3 \%$, women respectively in the three groups. Even in the third trimester of pregnancy, $37.4 \%$ women remained $<45.0 \mathrm{~kg}$ in the non-FL group as compared to $13.8 \%$ and $12.7 \%$ in the supplemented and the un-supplemented groups of FL group, respectively $(\mathrm{p}<0.05)$

\begin{tabular}{|c|c|c|c|c|c|}
\hline \multicolumn{6}{|c|}{ Table II - Details of Maternal Anthropometry During Pregnancy } \\
\hline \multirow{2}{*}{ Maternal Anthropometry } & \multicolumn{2}{|c|}{ FL Group } & \multirow{2}{*}{ Non-FL (C) } & \multirow{2}{*}{ p value } & \multirow{2}{*}{ Significance between } \\
\hline & Supplemented (A) & Un-supplemented (B) & & & \\
\hline & & 16 Weeks(1) & & & \\
\hline \multirow[t]{2}{*}{$\begin{array}{l}\text { 1.(a) Weight }(\mathrm{kg}) \\
\text { (b) MAC }(\mathrm{cm}) \\
\text { (c) Abdominal girth }(\mathrm{cm}) \\
\text { (d) Hemoglobin }(\mathrm{g} / \mathrm{dl})\end{array}$} & $\begin{array}{c}43.2 \pm 4.1 \\
22.2 \pm 1.6 \\
69.1 \pm 19.7 \\
10.0 \pm 1.0 \\
\end{array}$ & $\begin{array}{l}42.9 \pm 4.1 \\
22.2 \pm 1.7 \\
68.5 \pm 3.7 \\
10.1 \pm 2.8 \\
\end{array}$ & $\begin{array}{c}42.1 \pm 4.9 \\
22.8 \pm 1.8 \\
67.4 \pm 4.4 \\
9.1 \pm 0.9 \\
\end{array}$ & $\begin{array}{c}<0.01 \\
<0.0001 \\
0.02 \\
<0.0001 \\
\end{array}$ & $\begin{array}{c}\text { A vs C \& B vs C } \\
\text { Cvs A \& B } \\
\text { A vs B \& C } \\
\text { C vs A \& B } \\
\end{array}$ \\
\hline & & 28 Weeks(2) & & & \\
\hline \multirow[t]{2}{*}{$\begin{array}{l}\text { 2.(a) Weight }(\mathrm{kg}) \\
\text { (b) MAC }(\mathrm{cm}) \\
\text { (c) Abdominal girth }(\mathrm{cm}) \\
\text { (d) Hemoglobin }(\mathrm{g} / \mathrm{dl})\end{array}$} & $\begin{array}{c}45.9 \pm 4.0 \\
22.4 \pm 1.6 \\
78.4 \pm 3.5 \\
9.8 \pm 1.0\end{array}$ & $\begin{array}{c}45.8 \pm 4.5 \\
22.3 \pm 1.7 \\
78.6 \pm 4.3 \\
9.7 \pm 1.2\end{array}$ & $\begin{array}{c}44.9 \pm 5.1 \\
22.6 \pm 1.8 \\
74.2 \pm 5.0 \\
8.8 \pm 1.0\end{array}$ & $\begin{array}{c}0.004 \\
<0.0001 \\
<0.03 \\
<0.0001\end{array}$ & $\begin{array}{c}\text { A \& B vs C } \\
\text { C vs A \& B } \\
\text { B vs C } \\
\text { A \& B vs C }\end{array}$ \\
\hline & & 36 weeks(3) & & & \\
\hline $\begin{array}{l}\text { 3.(a) Weight }(\mathrm{kg}) \\
\text { (b) MAC }(\mathrm{cm}) \\
\text { (c) Abdominal girth }(\mathrm{cm}) \\
\text { (d) Hemoglobin }(\mathrm{g} / \mathrm{dl})\end{array}$ & $\begin{array}{c}49.8 \pm 4.4 \\
22.5 \pm 1.7 \\
89.9 \pm 4.5 \\
9.7 \pm 1.0\end{array}$ & $\begin{array}{c}48.9 \pm 4.5 \\
22.6 \pm 2.0 \\
89.3 \pm 4.6 \\
9.5 \pm 1.0\end{array}$ & $\begin{array}{c}46.9 \pm 5.2 \\
22.7 \pm 1.8 \\
85.2 \pm 5.2 \\
8.8 \pm 1.1\end{array}$ & $\begin{array}{l}<0.0001 \\
<0.02 \\
<0.0001 \\
<0.0001\end{array}$ & $\begin{array}{l}\text { C vs A \& B } \\
\text { A vs C } \\
\text { C vs A \& B } \\
\text { C vs A \& B }\end{array}$ \\
\hline 4. Wt. gain in pregnancy $(\mathrm{kg})$ & $7.5 \pm 1.0$ & $6.3 \pm 0.9$ & $5.6 \pm 1.1$ & $<0.001$ & C vs A \& B \\
\hline
\end{tabular}

Table 2: The total increase in abdominal girth was about $21 \mathrm{~cm}$ in the FL group and $17 \mathrm{~cm}$ in the non-FL group. These differences were significant $(\mathrm{p}<0.001)$. The change in mid-arm circumference during pregnancy was not significant in all the three groups at 36 weeks of gestation.

\section{Hemoglobin and Dietary Intake}

At 28 weeks, the mean hemoglobin decreased by 0.2 and 0.4 $\mathrm{g} / \mathrm{dl}$ amongst the FL group (supplemented and un-supplemented, respectively) and $0.3 \mathrm{~g} / \mathrm{dl}$ in non-FL group women. At 36 weeks, there was further fall of 0.1 and $0.2 \mathrm{~g} / \mathrm{dl}$ in the supplemented and the un-supplemented FL groups, whereas the non-FL group wom- en showed no fall. These hemoglobin changes were significantly $(\mathrm{p}<0.001)$ different Table 2.The dietary intake between 16-28 weeks did not change in any of the groups. The average caloric intake was $1650 \mathrm{kcal}$ per day and protein intake around $52 \mathrm{~g}$ per day. By about 36 weeks of pregnancy, FL supplemented group women received $1676 \pm 200 \mathrm{kcal} /$ day as compared to $1654 \pm 198 \mathrm{kcal} /$ day for the un-supplemented FL group. 
Citation: Jain G, Zuber M, Bisen V(2017) Impact of Female Literacy and Maternal Nutrition on Birth Weight of Infant in Rural Areas of Uttar Pradesh, India. J Community Med Public Health: CMPH-107.

\section{Effect on Birth Weight and Gestation}

In the FL village group, birth weight for supplemented women was significantly higher by $58 \mathrm{~g}$ as compared to un-supplemented women. The birth weight in un-supplemented FL group was $25 \mathrm{~g}$ higher as compared to non FL group. Women in FL supplemented group had a significantly smaller proportion of low birth weight babies (14.4\%) compared to FL un-supplemented (20.4\%) and non-FL group women (26.3\%). The prevalence of pre-term births was $2.0,2.4$ and $4.3 \%$ in the supplemented and un-supplemented
FL group and non-FL group respectively $(\mathrm{p}<0.001)$.

\section{Determinants of Birth Weight}

Multiple regression analysis revealed that weight gain in pregnancy, length of gestation and caloric intake in the third trimester made significant contribution to birth weight in both the FL and non-FL group Table 3.In addition, pre-pregnancy height and hemoglobin at 36 weeks made significant contribution to birth weight in FL group only.

\begin{tabular}{|c|c|c|c|c|c|c|c|}
\hline \multicolumn{8}{|c|}{ Table 3: Multivariate Analysis of Determinants of Birth Weight in FL and non-FL Group } \\
\hline \multicolumn{2}{|c|}{ Variables } & \multicolumn{3}{|c|}{ FL } & \multicolumn{3}{|c|}{ Non-FL } \\
\hline & & Coefficient & SE & $\mathbf{p}$ & Coefficient & SE & $\mathbf{p}$ \\
\hline \multicolumn{2}{|c|}{ Constant } & -865.28084 & 478.29463 & & -129.838883 & 489.685419 & \\
\hline \multicolumn{2}{|c|}{ Calories } & 0.16645 & 0.04546 & 0.0003 & 0.226384 & 0.054686 & 0.0000 \\
\hline \multicolumn{2}{|c|}{ Gestation } & 24.98118 & 8.30030 & 0.0027 & 27.16507 & 7.625302 & 0.0004 \\
\hline \multicolumn{2}{|c|}{ Hemoglobin } & 18.53742 & 8.77162 & 0.0349 & 4.238330 & 9.995086 & 0.6717 \\
\hline \multicolumn{2}{|c|}{ Weight gain } & 155.90639 & 11.35094 & 0.0000 & 83.521083 & 10.446403 & 0.0000 \\
\hline \multirow[t]{3}{*}{ Pre-pregnancy } & Height & 6.35163 & 2.481886 & 0.0107 & 1.934464 & 2.582162 & 0.4541 \\
\hline & Weight & -0.44979 & 2.88339 & 0.8761 & 10.682159 & 3.408719 & 0.0018 \\
\hline & $\begin{array}{c}\text { Mid Arm } \\
\text { Circumference(MAC) }\end{array}$ & 9.139508 & 6.71613 & 0.1740 & 2.152766 & 8.693745 & 0.8045 \\
\hline
\end{tabular}

Table 3: Multivariate Analysis of Determinants of Birth Weight in FL and non-FL Group.

\section{Discussion}

Literacy for females has very far reaching implications both for society as well as the recipient females. Literacy for females is a crucial input for developing and preserving human resource development, which in the ultimate analysis is a national asset. The main problem associated with women's health in India during pregnancy is their low levels of education and nutrition. Women's low level of literacy rate is definitely an important cause of their ill health and nutrition deficiency and also of the infants [3].

The present study was designed to evaluate the effects of Female Literacy, an important intervention provided by the Government of India in the Integrated Child Development Services(ICDS) and maternal nutrition on pregnancy outcome during the years 2011-2016. This is an important research question that arises on the ICDS scheme about their usefulness as these services have already being extended to cover all the blocks and urban slum areas without any improvement in Female literacy and quality of nutrition supplementation in those areas. Furthermore, the nutritional status of women in various parts of India is similarly poor, with lower weight gain in pregnancy $[1,4]$.

There is a definite need to provide women, the information related to health issues like importance of adequate nutritious diet, how to maintain their health, how to take care of minor illnesses, to know about the treatments of major illnesses and to understand the relative risks of malnourishment and risk or benefits of any treatment offered to them during pregnancy and its relative impact on the infant. Improving female literacy mainly for creating health awareness during pregnancy will thus be beneficial for improving health of both mother and infant in India[6,7].

In several other studies, low weight gain during pregnancy has been observed in undernourished women, e.g. $6.4 \mathrm{~kg}$ in Gambia [5], $7.6 \mathrm{~kg}$ in Taiwan [8,9] and $5.5 \mathrm{~kg}$ in East Java[10]. In Bangladesh [11]Urban high class gained $6.7 \mathrm{~kg}$ and low social class gained $5.5 \mathrm{~kg}$. Nutrition intervention in most of these studies improved weight gain in pregnancy and marginally improved the birth weight [12].

The pregnant women of Mohanlalganj in this study showed only marginal increase in energy intake and poor weight gain. Hemoglobin concentration between the 16 and 36 weeks reduced by $6 \%$ in the supplemented (Group A) and 6.9\% in un-supplemented area (Group B), with negligible change in the non-FL group (Group C) [13]. Reported their study that hemoglobin decrease by $1.7 \%$, $12.5 \%$ and $10 \%$ by 5,8 and 9 month of gestation, respectively. These findings suggest that the FL group women (Group A and B) could increase blood volume only to around $1 / 3$ of the expected and the non-FL group (Group C) had negligible expansion thereby explaining the need of literacy and nutrition during pregnancy as the fall in hemoglobin in second half of pregnancy is important for reducing pre-term and low birth weight deliveries [14].

As per the Integrated Child Development Services guidelines 


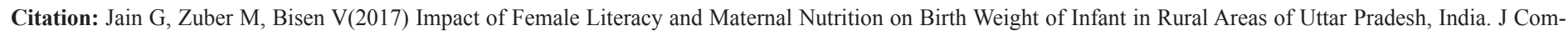
munity Med Public Health: CMPH-107.

women should receive 450-500 kcal with $20 \mathrm{~g}$ protein per day in the latter half of pregnancy; this should provide around 45,000$50,000 \mathrm{kcal}$ extra supplement in pregnancy. This was neither reflected in their dietary intake nor in weight gain during pregnancy in the results obtained. The possibility of food sharing in these poor families remains an important possibility for these observations. Inspire of very low level of supplementation as compared to the un-supplemented group, the positive achievements were: (a) lower percentage of low birth weight deliveries (14.4\% vs $20.4 \%$ ); (b) more newborns weighed $>3000 \mathrm{~g}(16.2 \% \mathrm{vs} 11.0 \%)$; (c) $100 \mathrm{~g}$ extra gain in maternal weight; and (d) the gestational age increased by 0.3 week $(p<0.001)$. A comparison of un-supplemented FL group (Group B) with non-FL women (Group C), showed 44.2\% reduction in pre-term births and $23.1 \%$ reduction in low birth weights. These achievements can be attributed to Female literacy provided in the Integrated Child Development Services scheme in un-supplement FL (Group B).

The Integrated Child Development Services Scheme(ICDS) to a large extent can be compared to the Women-Infant-Child (WIC) supplementation program of the USA $[9,15]$ providing milk, cheese, eggs, iron fortified cereal, beans, butter and $100 \%$ fruit juice (900 kcal/day). In WIC supplemented group (pregnancies = 1154673; during 1972-80) there was increase in birth weight by $23.9 \mathrm{~g}$ and gestational age by 0.2 day; reduction in pregnancy wastage (fetal mortality reduced by $2.3 / 1000$ ), small for gestational age births (reduced by $1.1 \%$ ) and maternal weight increased by $70 \mathrm{~g}$. Among women receiving nutrition supplement during second pregnancy, birth weight increased by $136 \mathrm{~g}$. In contrast, the present study on rural women had several well known factors predisposing for a small size baby: short stature, under-weight mothers and low mid-arm circumference (early as well as current under-nutrition). The normal pregnancy contributes $20 \%$ extra weight over the prepregnancy weight. For the mean height of the present study women, the expected weight should have been around $49 \mathrm{~kg}$, which at term with $20 \%$ increase would be $59 \mathrm{~kg}$. The study women however had a mean weight of $42.5 \mathrm{~kg}$ (around $86.7 \%$ of the expected). To approach the desired weight of $59 \mathrm{~kg}$ the gain should be 16.5 $\mathrm{kg}$ (deficit + required pregnancy gain). This will require 460-490 $\mathrm{kcal} /$ day extra from 12th week of gestation or before for ideal pregnancy outcome. The present study women gained an average weight of $6.3 \mathrm{~kg}$ (baby $=2.7 \mathrm{~kg}+$ placenta $0.4 \mathrm{~kg}+$ uterus + blood 3-4 kg) thus maintaining a deficit balance. Earlier studies in the same area revealed that treatment of anemia in pregnant women had also resulted in better birth weight[16].

\section{Conclusion}

The present study demonstrated that female education improved weight gain in pregnancy and birth weight with reduction in pre-term and low birth weight deliveries with an addition that nutritional supplements if provided along with literacy had a great- er impact in poor population of rural areas in which the study was conducted.

Based on the results, the suggestions would involve expanding female education initiatives along with providing nutritional supplements to females during pregnancy in poor population of rural areas. These two initiatives do not necessarily need to be compounded, but their effects are expected to be very interrelated provided that both the female education and nutritional supplementation access were equally distributed. It is important to remember that women's literacy is statistically significant in predicting health indicators during pregnancy and so the suggestion would be to equally expand the present education and health networks in the poor population of rural areas and urban slums of the country.

\section{References}

1. Tripathi AM, Agarwal DK, Agarwal KN, Devi RR, Cherian S (1987) Nutritional status of rural pregnant women and fetal outcome. Indian Pediatr 24:703-712.

2. Kandpal E, Baylis K, Arends-KuenniningM (2012) Empowering Women through Education and Influence: An Evaluation of the Indian MahilaSamakhya Program. IZA Discussion Paper No. 6347.

3. Ram F and Singh A (2006) Is antenatal care effective in improving maternal health in rural Uttar Pradesh? Evidence from a district level household survey. J Biosoc Sci38: 433-438.

4. National Nutrition Monitoring Bureau. Report of Repeat Surveys (198890). National Institute Nutrition 1991, Hyderabad.

5. Prentice AM, Whitehead RG, Watinson M, Lamb WH, Cole TJ (1983) Prenatal dietary supple-mentation of African women and birth weight. Lancet 321: 489-492.

6. Frey RS, \& Field C(2000) The determinants of infant mortality in the less developed countries: cross-national test of five theories. Soc Indic Res52: 215-234.

7. Gokhale MK, RaoSS, GaroleVR (2002)Infant Mortality in India: Use of Maternal and Child Health Services in Relation to Literacy Status. J Health PopulNutr20: 138-147.

8. McDonald EC, Pollit, Mueller W, Hsuch AM, Shervig R (1981) The Bacon Chow study: Maternal nutrition supplementation and birth weight of offspring. Am J ClinNutr34: 2133-2144.

9. Adair LS, Pollit E (1985) Outcome of maternal nutritional supplementation: A comprehensive review of the Bacon Chow study. Am J ClinNutr41: 948-978.

10. Kardjati S, Kusin JA, Schofield WM (1990) Energy supplementation in the last trimester of pregnancy in East Java Indonesia: Effect on maternal anthropometry. Am J ClinNutr 52: 987-994.

11. Canosa CA (1989) Intrauterine growth retardation in India and BaglaDesh. In: Intrauterine growth Retardation. Ed. Senterre J, Nestle Nutrition Workshop Series, New York, Raven Press: 183-204.

12. Kramer MS (1993) Effects of energy protein intakes on pregnancy outcome. An overview of the research evidence from controlled clinical trials. Am J ClinNutr 58: 627-635.

13. Paintin DB, Thomson AM, Hytten FE (1966) Iron and the hemoglobin level in pregnancy. J ObstetGynec Brit CmmWlth 73: 181-186. 
Citation: Jain G, Zuber M, Bisen V(2017) Impact of Female Literacy and Maternal Nutrition on Birth Weight of Infant in Rural Areas of Uttar Pradesh, India. J Community Med Public Health: CMPH-107.

14. Steer P, Alam MA, Wadsworth J, Welch A(1995) Relation between maternal hemoglobin concentration and birth weight in different ethnic groups. Brit Med J310: 489- 491.

15. Rush D, J Leighton, NL Sloan, JM Alvir, DG Horvitz, et al. (1988) The national WIC-evaluation: Evaluation of the special supplement food program for women infants and children. Am J ClinNutr 48: 484-511.
16. Agarwal KN, Agarwal DK, Mishra KP (1991) Impact of anemia prophylaxis in pregnancy on maternal hemoglobin, serum ferritin and birth weight. Indian J Med Res 94:277-280. 